\title{
Comparison of Essay Type and Multiple Choice Questions for Theoretical Formative Assessment among Second Phase MBBS Students in Microbiology
}

\author{
T.M. Nandan ${ }^{1} *$, G. Latha ${ }^{1}$, Dhayakani Selvakumar ${ }^{3}$ and C.N. Veena ${ }^{4}$ \\ ${ }^{1}$ Department of Microbiology, PES Institute of Medical Sciences and Research, Kuppam, \\ Chittoor Dist., A.P, India \\ ${ }^{3}$ Medical Education Unit (Retd), Christian Medical College, Vellore, T.N, India \\ ${ }^{4}$ Department of Physiology, PES Institute of Medical Sciences and Research, \\ Kuppam, Chittoor Dist., A.P, India \\ *Corresponding author
}

\section{A B S T R A C T}

\section{Keywords}

Essay, Multiple choice questions, theoretical formative assessment, MBBS students, Microbiology

Article Info

Accepted:

17 April 2017

Available Online:

10 May 2017
"Learning" is a continuous process and assimilation of information takes place over a period of time. Formative assessments in Microbiology with only essay type of questions are often perceived as difficult considering time constraints to the learning processes especially during this assimilatory phase. So, it is worthwhile to include multiple choice questions for formative assessments as a more comprehensive and supportive tool to aid in student directed teaching and learning especially in Microbiology. Sets of 42, 42 and 27 students in the phase 2 of MBBS were administered with 3 sets of essay type and multiple choice type of questions on Microbiology and the performance assessed and compared. A questionnaire based perceptions study about the assessment methods was also carried out using a Likert 5 point scale on a set of 45 students for the feedback process. Performance in MCQ based formative assessment in Microbiology was significantly better than that in essay type of assessment. Mean score overage for MCQs: $32.52 \%, \mathrm{P}<0.05, \mathrm{~N}=111$. The students also indicate remarkable preference for MCQ based formative assessment. Second phase MBBS students found MCQ type of formative assessment more comprehensive and pleasant than the essay type of assessment in Microbiology during the assimilatory phase of their study period.

\section{Introduction}

Although innumerable studies comparing multiple choice questions (MCQs) and essay type questions have been performed in many areas of medicine, studies addressing special attributes of Microbiology have hardly been addressed. The very fact that MBBS students are systematically introduced to the relatively obscure world of microbes only in their $2^{\text {nd }}$ phase makes the specialty extraordinary and thus creates a sense of necessity to wake up from this microbiologic oblivion.
Moreover, the science of Microbiology is hardly incorporated in the high school and pre-university curricula given its inherent complexities like multitudes of identification methods, bio-safety and bio-security issues to list a few exemplary ones. This is in stark contrast to other specialties like Pathology and Pharmacology, which although vast are in factual continuum with Anatomy and Physiology respectively and medicos spend their first professional in spite of the objective 
knowledge about transmission of infectious agents excepting for the bare minimum protection taken through hand washing and common sense.

"Learning" is a continuous process and is achieved by sequential delivery of lessons to students within an area of specialty. Assimilation of information in various domains of learning takes place over a period of time depending on multiple factors (McLeod, 2015; David, 2003). Formative assessments with only essay type of questions are often perceived as difficult and less objective considering time constraints to the learning processes especially during this assimilatory phase (Lambert et al., 2003).

Key factual educational information covering the entire syllabus, also often covering all the domains of learning can be assessed by multiple choice questions, which have already been in place as screening as well as summative assessment tools at national and international levels (Kress et al., 2012; Ronald, 2007; Krathwohl, 2002; Scoulle et al., 1994).

So, it is worthwhile to include multiple choice questions for formative assessments as a more comprehensive and supportive tool to aid in student directed teaching and learning in Microbiology in view of the implicit need as explained above (David, 2003).

The main aim of the study has been to make medical education in Microbiology more comprehensive and pleasant for students during the assimilatory phase of learning and beyond. The objectives have been: to compare performance in descriptive and multiple choice types in formative assessment among second phase MBBS students in Microbiology and to study perceptions of the students about the assessment methods in Microbiology.

\section{Key evaluation questions}

Is there any significant difference in performance with the two methods during the assimilatory phase of learning in Microbiology?

Is the multiple choice method perceived to be more acceptable to students who are in the assimilatory phase of learning Microbiology?

\section{Materials and Methods}

The study was performed in the medical institution in Kuppam, Chittoor District of Andhra Pradesh between May 2015 and October 2015 with approval from the Institutional Research and Ethics Committee. Before commencement, all the students in their $2^{\text {nd }}$ professional were briefed about the meanings of essay type and multiple choice questions, the study administration plan and were informed that their scores would be compared in both the types of assessment. Sets of students who consented for participating: set of 42,42 and 27 students studying in the phase 2 of MBBS while in their fourth term (passed $>6$ months in their phase 2) were administered with 3 sets (monthly one set) of essay type and multiple choice type of questions on Microbiology based on all the appropriate teaching-learning domains and the performance assessed and compared. To make the study as natural as possible, the three consecutive MCQ tests were administered soon after each of the three consecutive routinely scheduled institutional monthly tests (scheduled with other $2^{\text {nd }}$ professional subjects) during the study period. At the end, a questionnaire based perceptions study about the assessment methods was also carried out using a previously adopted perception questionnaire on Likert 5 point scale on a set of 45 students for the qualitative feedback process (Parmenter et al., 2009). Scores obtained by students in essay and 
multiple choice types of assessment were analyzed for significance by student $\mathrm{T}$ test. The percent difference in performance scores were calculated for confidentiality of the obtained scores. The students' perceptions scores from the Likert scale were compared using percent and mean preferences for the two modes of assessment.

Perception questionnaire (modified from Parmenter et al., 2009)

(P1) I prefer multiple choice questions to essay questions.

(P2) I prefer essay questions to multiple choice questions.

(P3) Multiple-choice easier: I only need to recognize correct answers.

(P4) Multiple-choice easier: I can eliminate obviously wrong answers.

(P5) Multiple-choice easier: I might guess correctly even if I don't know.

(P6) Multiple-choice harder while learning new topics: I need to know minute details.

(P7) Essay harder while learning new topics: I must fully study the syllabus to produce good answers.

(P8) Essay less fair: I feel writing skill affects scoring and passing.

(P9) Essay makes me more anxious while writing.

(P10) I can expect more success rate in multiple choice questions.

\section{Results and Discussion}

A total of 111, from the 3 not mutually exclusive sets of $2^{\text {nd }}$ professional medical students participated in this theoretical formative assessment study. Forty five students who took part in the study participated in the qualitative perception study for the feedback process. Performance in the formative MCQ based assessment in Microbiology is significantly better than that in essay type of assessment as depicted in chart and table 1 . Mean score overage for MCQs: $32.52 \%, \mathrm{P}<0.05, \mathrm{~N}=111$. The students also indicate remarkable preference for the formative MCQ based assessment over the essay type in Microbiology as depicted in chart and table 2. Overall preference: $82.22 \%$ (P1) for MCQs Vs 22.22\% (P2) for essay. Mean perception preference scores for the formative essay and MCQs are 2.888 and 3.955 respectively (Fig. 1).

Analysis of the factors P3 and P4 in table 2 reveals that the students were much comfortable answering the MCQs that they could easily recognize the correct answers to the questions (82.23\%), eliminate obviously wrong answers $(91.11 \%)$. Analysis of the factor P5 suggests that they might correctly guess the right answers even if they could not recall them immediately $(64.45 \%)$. This shows that the vaster amount of shallow information pertaining to Microbiology that is 
based on recalling from memory is judiciously assessed by MCQs.

P6 and P7 results compare and contrast the students' perceptions regarding deep understanding related to Microbiology. Though they feel that answering questions that require in depth study of the subject is challenging in both the methods of assessment, they find essays harder $(75.56 \%)$ than the MCQs $(62.22 \%)$ for demonstrating their ability to grasp minute details regarding the subject.

In P8, enquiring about writing skills that includes handwriting and organizing skills, a great majority of the students $(75.56 \%)$ perceived that it affects their scoring and even passing the test. Considerable numbers $(42.22 \%)$ of them felt that their anxiety level goes up while answering essay type of questions (P9). P10 re-affirms the overall benefits to the students by the MCQ based formative assessment by the assurance of favorable expectations, (i.e., about their success rates) $84.45 \%$ of them agreeing for it.

Studies comparing essay type and multiple choice questions (MCQs) for assessment in Microbiology involving MBBS students are very few and those that analyze the need for applying the same for formative assessments are fewer. The present study aimed at the usual comparison between these two types of assessment, focuses on the special characteristics of Microbiology as a subject that is freshly introduced to medical students in their second professional term.

The assessment methods: written examinations form mainstay of theoretical summative assessment in Microbiology in addition to practical skills assessment through performance and/or interpretation of tests like all other branches of medicine. The theory paper consists of long essay, short essay, and short answer questions, which basically fall into essay type of questions. The theoretical formative assessment also takes place with a similar pattern of essay questions by convention. As per the definition of an essay question in Merriam Webster Dictionary, 'an examination question that requires an answer in a sentence, paragraph, or short composition' (Merriam-Webster, 2017), even short answer questions fall under an essay type question. An essay type of question is basically an open ended question without any option to choose the single right answer from a group of distracters as is the case in a typical MCQ with the stem leading to 4-5 options. The stem of an MCQ can be variably framed from a simple phrase to the narration of a procedure or a clinical scenario or even pictures and illustrations.

Advantages of MCQs over essay type questions: All domains of learning can be assessed by appropriately constructed multiple choice questions. With the possibility of inclusion of clinical case or even test procedural scenarios and microbial morphological descriptions, as is applicable for Microbiology, MCQs have greater flexibility as tools of assessment of all teaching-learning domains. This application aspect of MCQs has been elaborately explained by researchers on Bloom's taxonomy as that which serves as the backbone for many teaching philosophies, in particular those that lean more towards skills rather than content alone (Krathwohl, 2002). In general, teachers from diverse fields of study prefer MCQs over essay type for assessments that involve testing both lower as well as higher orders of learning (Neşet, 2015).

By providing some background information about any scenario, MCQs take away the burden of memorizing each and every aspect of the vast, diverse, exotically factual nature 
of the subject and allow the examinees to come at a reflective educated guess, which will not be possible to occur just by chance. Handwriting skill, which comes in the way of organizing an essay, will not come in the way of assessment that is independent of the examiner's perceptions and presumptions (Pai et al., 2010). Moreover, organizing skills required to compile an essay are known to improve with the spent time with the subject over a considerable period of time, usually, by the end of the course/specified period. This improved understanding and proficiency come from actively performed repeated studies of inter-relations within the subject and that of the overlapping aspects of the other $2^{\text {nd }}$ professional subjects largely (horizontal integration), and to a greater extent, of the linear-relations with those of the $1^{\text {st }}$ and the $3^{\text {rd }}$ professional subjects (vertical integration). The skill development that takes place at higher orders of thinking complies well with the globally much emphasized focus on multiple literacies and modalities of learning and hence the resultant rapidly emerging field of 'integration of diverse disciplines' aimed at overall human development (Kress et al., 2012). Nevertheless, in depth studies have gone on to suggest that students generally prefer multiple-choice but become more enthusiastic about essays when they are well prepared for exams (Parmenter et al., 2009).

A study among first year medical students in Physiology also revealed that insufficient knowledge and students' inability to establish a logical sequence about the learnt information are the main reasons for their poor performance in essay questions compared to MCQs (Oyebola et al., 2000). Pepple et al., reports that the essay questions in Physiology with long answers help students to express their cognitive skills in higher areas such as analyses and applications is difficult to apply to Microbiology where much of the vast knowledge database is basically derived from performance of risky, tedious and time consuming in vitro experiments about an array of pathogenic microbes and hence has hardly been worthy of incorporation in core curriculum for medical students at undergraduate level (Pepple et al., 2010).

A perceptions study by Shazia et al., 2016, in Mumbai, India, on the importance of feedback in teaching and learning Microbiology among phase 2 MBBS students, the students suggested the usefulness of weekly multiple choice questionnaires in the subject in addition to monthly tests. This further highlights the felt need for additional modes of assessment during the assimilatory phase of learning.

In a related study on $2^{\text {nd }}$ phase MBBS students' perceptions about their performance and preferences for a variety of essay type questions in Microbiology, majority of them favored the relatively more objective, problem based modified essay questions (MEQ) and structured essay questions over the traditional long essay questions. However, other detailed analysis questions revealed a mixed opinion about the ease and effectiveness about the methods of assessment using any type of essay questions. Out of 154 students who preferred MEQ as a method for testing clinical reasoning ability only $52 \%$ students found it easier to answer. Similarly among 149 students who believed MEQ as a method to improve problem solving skills, only $49 \%$ of the students assumed it as a means to test knowledge of the topic adequately and only about $40 \%$ thought that it will fetch them more marks. Although the long essay type questions were considered to test answer presentation skills by $59 \%$ of students, only about $12 \%$ found them easier to answer, 9\% preferred to answer and only one student considered it as time saving (Naik et al., 2015). 
Microbiology is unique: Suggestions and opinions of a few already passed out medical graduates from across the country who have contributed to this area of interest through social media clarify these special features.

Sarath, 2015 states: "Microbiology means the study of micro organisms. But don't think that it is very small. In fact this subject is a stand out example of how small organism can increase the mental stress of a medical student. It is one of the most memories consuming subject. Bacteriology is vast and very difficult to remember. For me, it was difficult to remember the virulence factors of each bacterium. As usual the initial exams were tragedies like 'Othello' of Shakespeare."

Fadnis, 2016, states: "Microbiology: There are so many viruses and bacteria that you tend to get confused between everything".

Datar, 2017, states: "Microbiology deals with bacteria, viruses, parasites and immunology. You'll learn about the plethora of pathogenic microorganisms. Though you can understand certain things, but there's no other option than mugging up for most of it, you'll have to mug up the lab diagnoses anyhow".
In spite of these attributes as a volatile subject, Microbiology grabs its attention by being universally applicable to all other areas of clinical medicine including nursing and other allied health sciences, a virtual basic medical science. This has not been the case until recently when the world has started witnessing the emergence of difficult to treat multidrug resistant organisms and the threat of 'post antibiotic era', although in the recent past, Medicine as a profession attained its height through several Nobel Prize winners from the specialty, which the entire world has thankfully acknowledged. The difficulties faced by medical students while they encounter and start assimilating this subject for the first time in their second professional will not be addressed until the teachinglearning-assessment processes are made student friendly by favorably enhancing the retainability of the related essential knowledge, attitude and skills that will result in long term self directed learning for the betterment of the field and the entire medical profession as a whole.

Table.1 Mean \% difference in MCQ scores over essay scores

\begin{tabular}{|l|l|c|}
\hline & $\begin{array}{l}\text { Mean \% } \\
\text { difference in } \\
\text { MCQ scores over } \\
\text { Essay scores }\end{array}$ & \\
\hline TEST-1 (n=42) & $29.047 \%$ & 0.0326 \\
\hline TEST-2(n=42) & $38.891 \%$ & 0.0019 \\
\hline TEST-3(n=27) & $29.633 \%$ & 0.049 \\
\hline $\begin{array}{l}\text { TEST-TOTAL } \\
\text { (N=111) }\end{array}$ & $32.52 \%$ & 0.0278 \\
\hline
\end{tabular}


Table.2 Likert scale perception scores and percentages

\begin{tabular}{|c|c|c|c|c|c|c|c|c|c|c|c|}
\hline \multirow[t]{2}{*}{ Q.No } & \multicolumn{2}{|c|}{$\begin{array}{c}\text { STRONGLY } \\
\text { AGREE }\end{array}$} & \multicolumn{2}{|c|}{ AGREE } & \multirow[t]{2}{*}{$\begin{array}{l}\text { TOTAL } \\
\text { AGREE }\end{array}$} & \multicolumn{2}{|c|}{ NEITHER } & \multicolumn{2}{|c|}{ DISAGREE } & \multicolumn{2}{|c|}{$\begin{array}{l}\text { STRONGLY } \\
\text { DISAGREE }\end{array}$} \\
\hline & $\mathbf{N}$ & $\%$ & $\mathbf{N}$ & $\%$ & & $\mathbf{N}$ & $\%$ & $\mathbf{N}$ & $\%$ & $\mathbf{N}$ & $\%$ \\
\hline P1 & 14 & $31.11 \%$ & 23 & $51.11 \%$ & $82.22 \%$ & $\mathbf{0}$ & $0 \%$ & 8 & $17.78 \%$ & $\mathbf{0}$ & 0 \\
\hline $\mathbf{P 2}$ & 6 & $13.33 \%$ & 4 & $8.89 \%$ & $22.22 \%$ & 13 & $28.89 \%$ & 22 & $48.89 \%$ & $\mathbf{0}$ & 0 \\
\hline P3 & 21 & $46.67 \%$ & 16 & $35.56 \%$ & $82.23 \%$ & 4 & $8.89 \%$ & 4 & $8.89 \%$ & $\mathbf{0}$ & 0 \\
\hline P4 & 24 & $53.33 \%$ & 17 & $37.78 \%$ & $91.11 \%$ & 2 & $4.44 \%$ & 2 & $4.44 \%$ & $\mathbf{0}$ & 0 \\
\hline P5 & 13 & $28.89 \%$ & 16 & $35.56 \%$ & $64.45 \%$ & 8 & $17.78 \%$ & 7 & $15.56 \%$ & 1 & $2.22 \%$ \\
\hline P6 & 9 & $20 \%$ & 19 & $42.22 \%$ & $62.22 \%$ & 6 & $13.33 \%$ & 11 & $24.44 \%$ & $\mathbf{0}$ & 0 \\
\hline P7 & 18 & $40 \%$ & 16 & $35.56 \%$ & $75.56 \%$ & 4 & $8.89 \%$ & 5 & $11.11 \%$ & 2 & $4.44 \%$ \\
\hline P8 & 12 & $26.67 \%$ & 22 & $48.89 \%$ & $75.56 \%$ & 6 & $13.33 \%$ & 3 & $6.67 \%$ & 1 & $2.22 \%$ \\
\hline P9 & 6 & $13.33 \%$ & 13 & $28.89 \%$ & $42.22 \%$ & 11 & 24.44 & 14 & $31.11 \%$ & 1 & $2.22 \%$ \\
\hline P10 & 21 & $46.67 \%$ & 17 & $37.78 \%$ & $84.45 \%$ & 4 & $8.89 \%$ & 3 & $6.67 \%$ & $\mathbf{0}$ & 0 \\
\hline
\end{tabular}

Chart.1 Mean \% difference in MCQ scores over Essay scores

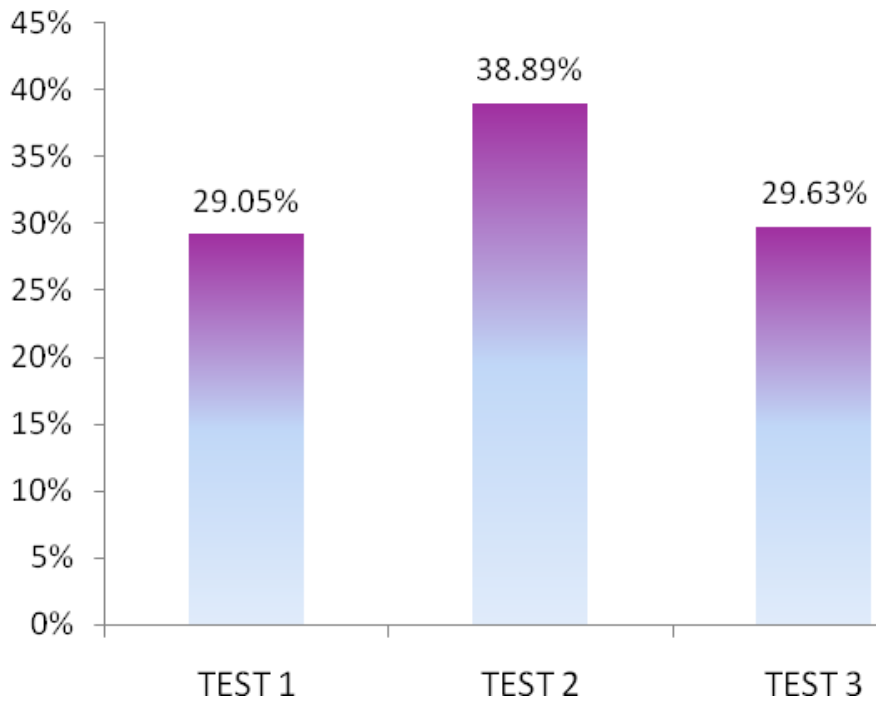


Fig.1 Mean perception preference scores for essay and MCQ

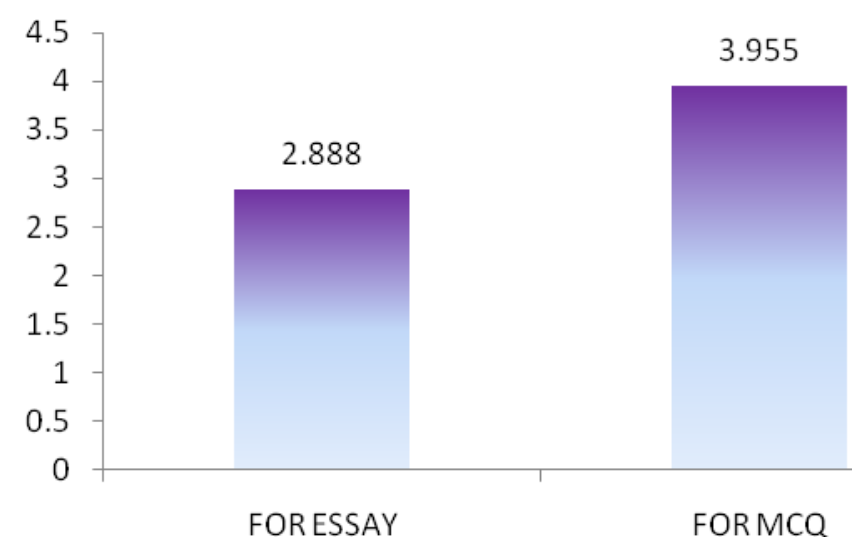

The exotic, lengthy, binomial Greek and Latin names, region specific common names of the organisms and the stories behind them, in addition to the disease entities, diseases epidemiology, the diverse antibiotic classes coupled with the threat of biosafety and biosecurity issues make a grand recipe for utter confusion and are an ultimate test for the human intellectual integrity! To avoid reentering the oblivion is hence a great challenge and must be carefully and sympathetically dealt with at the student level and at the professional level too.

Attitudes are subconsciously imparted during formal medical education about knowledge and skills in medicine and play crucial role in future professional success (Olthuis et al., 2003). In the study by Alam, 2011, 50\% of the student participants in their clinical years indicated that they retained the most knowledge from physiology coursework in contrast to only $20 \%$ and $19 \%$ of them from Microbiology and Biochemistry coursework respectively. Another aspect of the same questionnaire revealed that the students in each clinical academic year ranked Microbiology (27\%) and Pathology (45\%) the lowest in terms of providing lists of references and course specifications. These show that Microbiology and similar subjects must undergo thorough curricular changes for better clinical integration and practice. Simplifying the incapacitating complexities of any area of study will go a long way in students adopting lifelong self directed learning.

In conclusion, second phase MBBS students found MCQ type of formative assessment more comprehensive and pleasant than the essay type of assessment in Microbiology during the assimilatory phase of their study period and would prove to be complementary to mid-term and pre-final essay type exams. A variety of more realistic techniques may have to be adopted in teaching-learning and assessment methods in Microbiology during the assimilatory period and MCQs demonstrate to be promising in making the subject more accommodative to the budding young minds and will go extra miles in their life long endeavor with Clinical Microbiology, Infectious Diseases and Infection Control and thus encourage them to be ever ready to deal with any emerging and re-emerging infections anywhere in the world.

\section{Acknowledgements}

We are grateful to our colleagues, students and the management of PESIMSR, Kuppam and CMC, Vellore, for facilitating this wonderful learning experience. 


\section{References}

Alam, A. 2011. How do medical students in their clinical years perceive basic sciences courses at King Saud University? Ann. Saudi Med., 31: 58-61.

Datar M. 2017. What's 2nd year MBBS all about? (internet). Quora. Available from: https://www.quora.com/Whats-2nd-yearMBBS-all-about/answer/Mayank-Datar. (Accessed 17-03-2017).

David, M.K. 2003. ABC of learning and teaching in medicine: Applying educational theory in practice. $B M J, 326:$ 213-216.

Fadnis, A. 2016. How do I study each subject in MBBS (internet). Quora. Available from: https://www.quora.com/How-do-I-study-eachsubject-in-MBBS. (Accessed 17-03-2017).

Hui, M.E., Srinivasan, R., Peter, C.K.P. 2014. Can learning outcomes in cognitive domain be assessed effectively using multiple choice questions? A study in an undergraduate pharmacy curriculum. IeJSME, 8(3): 9-18.

Krathwohl, D.R. 2002. "A revision of Bloom's taxonomy: An overview". Theory Into Practice. Rout ledge, 41(4): 212-218.

Kress, G., Selander, S. 2012. "Multimodal design, learning and cultures of recognition". Internet and Higher Education, 15(1): 265-268.

Lambert, W.T.S., Cees, P.M.V. 2003. ABC of learning and teaching in medicine: Written assessment, 326: 643-645.

McLeod, S.A. 2015. Jean Piaget. Available from www.simplypsychology.org. Accessed on 1010-2015.

Merriam-Webster. 2017. Essay question. MerriamWebster Dictionary and Thesaurus. Available from: https://www.merriamwebster.com/dictionary/essay\%20question. (Accessed 05-04-2017).

Naik, T.B., Amruthkishan, K.U., Swaroop Rani, N.B., Wadekar, M.D., Mane, V., Biradar, A. 2015. Students perception on different formats of written assessment in Medical Education. $J$. Edu. Res. Med. Teach., 3(1): 8-12.
Neşet, D. 2015. Turkish Prospective Teachers' Perspective of Different Types of Exams: Multiple Choice, Essay and Computerized-type Testing. Essays in Education, Special Edition, 48-62.

Olthuis, G., Dekkers, W. 2003. Medical education, palliative care and moral attitude: some objectives and future perspectives, 37: 928-933.

Oyebola, D.D.O., Adewoye, O.E., Iyaniwura, J.O., Alada, A.R.A., Fasanmade, A.A., Raji, Y. 2000. A comparative study of students' performance in preclinical physiology assessed by multiple choice and short essay questions. Afr. J. Med. Med. Sci., 29: 201-205.

Pai, M.R.S.M., Sanji, N., Pai, P.G., Kotian, S. 2010. Comparative assessment in Pharmacology multiple choice questions versus essay with focus on Gender differences. J. Clin. Diag. Res., 4: 2515-2520.

Parmenter, David, A. 2009. Essay versus multiplechoice: student preferences and the underlying rationale with implications for test construction. Acad. Educational Leadership J., 13(2). Available from: The Dream Catchers Group, LLC. Accessed on 17-09-2015.

Pepple, D.J., Young, L.E., Carroll, R.G. 2010. A comparison of student performance in multiplechoice and long essay questions in the MBBS stage I physiology examination at the University of the West Indies (Mona Campus). $A d v$. Physiol. Educ., 34(2): 86-9.

Ronald, M.E. 2007. Assessment in medical education. N Engl. J. Med., 356: 387-96.

Sarath. 2015. My second year MBBS experience (internet). Type it out. Available from: https://www.typeitout.com/article/my-secondyear-mbbs-experience. (Accessed 10-03-2015).

Scouller, K.M. \& Prosser, M. 1994. Students' experiences in studying for multiple choice question examinations. Studies in Higher Edu., 19(3): 267-279.

Shazia, C., Sarala, M., Ashwini, R., Abhay, C. 2016. Learning and Teaching in Microbiology: Students' Perception. Natl. J. Integr. Res. Med., 7(6): 25-28.

\section{How to cite this article:}

Nandan, T.M., G. Latha, Dhayakani Selvakumar and Veena, C.N. 2017. Comparison of Essay Type and Multiple Choice Questions for Theoretical Formative Assessment among Second Phase MBBS Students in Microbiology. Int.J.Curr.Microbiol.App.Sci. 6(5): 1529-1537. doi: https://doi.org/10.20546/ijcmas.2017.605.167 